\title{
An Overview on the Genetic Determinants of Infertility
}

\author{
Ayesha Badar, Ansari AS* and Lohiya NK \\ Department of Zoology, University of Rajasthan, India
}

Received: 制: October 17, 2018; Published: 制: October 31, 2018

*Corresponding author: Ansari AS, Department of Zoology, University of Rajasthan, India

\begin{abstract}
Infertility is an emerging major health issue with innumerable causes, viz., testicular and ovarian disorders, advanced maternal age, obesity, chromosomal abnormalities, etc. Most of these causes are linked to the genetic disorders. Genetic causes of infertility can be divided into cytogenetic anomalies, gene defects and epigenetic aberrances. The causes of male infertility focuses on genetic factors impairing spermatogenesis and includes numerical chromosomal anomalies such as Klinefelter's syndrome, structural chromosomal anomalies such as Y-chromosome micro-deletions, certain single gene mutations, syndromic diseases and epigenetic mutations. The reasons behind female infertility include chromosomal anomalies like Turner's syndrome, genetic and epigenetic mutations, polycystic ovary syndrome, cystic fibrosis, gonadal dysgenesis and premature ovarian failure. Overall, the article overviews various genetic factors responsible for both male and female infertility.

Keywords: Genetic; Infertility; Chromosomal Abnormalities; Mutations; Spermatogenic Failure; Polycystic Ovary Syndrome; Premature Ovarian Failure; Cystic Fibrosis
\end{abstract}

\section{Introduction}

Infertility, the inability to conceive by natural means, is a worldwide problem affecting 8-12\% couple during their reproductive lives with high prevalence (10-15\%) in India. It is estimated that while female factor accounts for $40-50 \%$ of infertility among couples, infertility attributable to male factors is on the rise and constitutes $30-40 \%$ of infertility [1,2]. Infertility can be hormonal, related to age, exercise, obesity or infectious disease; it can be immunological, psychological, result from surgery or blockage, or be associated with defined abnormalities in the gametes. Many factors are implicated in the etiology of infertility, be it male associated or attributed to the female partner. These factors may be hormonal, infectious, immunological, surgical or psychological. Most of these factors have genetic basis involving several genes and gene products. In the future, pursuing the most promising genetic variants, mutations, or polymorphisms may provide clinically relevant therapeutics for infertile individuals. As more genes are discovered and the etiology of infertility disorders becomes well understood, the management and treatment of infertility will improve as well. Herein, the review presents the known genetic causes and their associations for both male and female infertility.

\section{Male Infertility}

\section{Structural Chromosomal Abnormalities (SCAs)}

It includes deletions, duplications, translocations (balanced, imbalanced and Robertsonian) and inversions. There are two alternative models that explain the aberration effect. First, it blocks spermatogenesis via abnormal chromosome synapsis in crossover and meiosis arrest. Second, the aberration disrupts a dosagesensitive gene, resulting in spermatogenesis arrest and infertility [3].

\section{Translocations}

Chromosomal translocations can be of two types, i.e., Robertsonian translocations involve acrocentric chromosomes (13, 14, 15, 21 and 22) and reciprocal translocations involve mutual exchange of chromosomal segments between autosomal and sex chromosomes. Chromosomal translocations may cause reductions in testicular volume and testosterone level, which may impact spermatogenesis, resulting in azoospermia or oligozoospermia and thereby, male infertility [4,5].

\section{Y Chromosome Deletions}

It is estimated that $19 \%$ of males diagnosed with idiopathic infertility have Yq (long arm) micro-deletions and between $50-70 \%$ of the non-recombining region of human $Y$ chromosome is composed of a variety of highly repeated DNA elements, the majority of which appear to be unique to the human Y chromosome. Deletions of the $\mathrm{Y}$ chromosome are likely to be consequence of these repeated elements causing intra-chromosomal recombination. There is a possibility that $\mathrm{Y}$ chromosome micro-deletions may also contribute to spermatogenic failure. The type and severity of structural anomalies depends on the location and size of the anomaly as 
well as the presence of inter-chromosomal effects during meiotic recombination [6].

\section{Chromosome Aneuploidy}

Down's syndrome is a complex genetic disease resulting from the presence and expression of 3 copies of the genes located on chromosome 21 (trisomy 21). In most cases, the extra chromosome stems from the failure of normal chromosomal segregation during meiosis (meiotic non-disjunction). The non-disjunction event is maternal in $<95 \%$ of cases, occurring primarily during meiosis I in the maturing oocyte, before conception. Down's syndrome occurs with an estimated frequency of 1 in 600 live births and 1 in 150 conceptions $[7,8]$.

\section{Aneuploidy of the X Chromosome}

Klinefelter's syndrome is a form of hypergonadotropic hypogonadism and infertility resulting from a supernumerary $\mathrm{X}$ chromosome (47, XXY). Classically, Klinefelter's syndrome is outlined by gynaecomastia, small, firm testes with hyalinization of seminiferous tubules, hypergonadotrophic hypogonadism and azoospermia. The 47, XXY karyotype with different prevalence rate in the general population $(0.1 \%)$, among infertile patients of azoospermic (11\%) and of oligozoospermic men $(0.7 \%)$ has also been reported. Men having Klinefelter's syndrome with chromosomal mosaicism (46, XY/47, XXY) are fertile and with non-mosaic or complete, are azoospermic and only a few have any spermatogenesis [6].

\section{Aneuploidy of the Y Chromosome}

In 47, XYY syndrome, men are otherwise healthy, while semen analyses frequently indicate oligozoospermia or azoospermia. It has been shown that germ cells with an extra Y chromosome from men with the 47, XYY karyotype have abnormal meiotic pairing, suggesting disrupted meiosis, eventual sperm apoptosis and subsequent oligozoospermia and infertility [9].

\section{Testicular Disorder of Sex Development (DSD)}

The DSD also known as 46, XX male syndrome, in which patients have an $\mathrm{X}$; Y translocation with Y-linked gene SRY is placed on one of the X chromosomes. 46, XX males with SRY and testicular DSD have normal male genitalia but show spermatogenesis arrest and develop severe testicular atrophy and azoospermia. The SRY encodes the critical testis-determining transcription factor that activates a number of downstream transcription factors involved in testes formation. SOX9 is a direct target of SRY, and it's over expression can mimic male development without SRY. Mutations and small duplications of the SOX9 upstream regulatory region were demonstrated in SRY-negative XX males. Alternatively, increased expression of SOX9 can be induced by steroidogenic factor 1 , NR5A1 and SOX3. Recently, R-Spondin 1 (RSP01) mutations were shown to cause an XX male condition [10].

\section{Small Supernumerary Marker Chromosomes}

Small Supernumerary Marker Chromosomes (sSMC) are structurally abnormal chromosomes that cannot be identified or characterized unambiguously by conventional banding cytogenetics alone. They can lead both to fertility problems and repeated abortions. The rate of sSMC presence in the normal population was recently determined to be $0.044 \%$, however, elevated to $0.125 \%$ in infertile groups. It was identified that after sSMC detection in connection with unexplained infertility in $\sim 60 \%$ of cases the origin of the SSMC can be characterized by application of the centromerespecific probes for chromosomes 14 and 15 [11-14].

\section{Myotonic Dystrophy 1}

Myotonic Dystrophy 1 (DM1) is a hereditary, autosomal dominant multi-system disorder characterized by the development of structural and functional abnormalities in the muscle membrane protein associated with muscular dystrophy, cardiac conduction disorders, cataracts, mental retardation and endocrine and reproductive defects. Progressive testicular atrophy is a prominent feature and occurs with an incidence of approximately $80 \%$. Histological abnormalities include hyalinization, atrophy, fibrosis of seminiferous tubules and reduced sperm numbers. Oligospermia and azoospermia are also reported in approximately $73 \%$ of DM1 patients [15-17].

\section{Single-Gene Disorders}

Single-gene mutations areinvolved in infertility, eitherby causing aberrant pubertal development, deficiency of pituitary hormones or affecting the gonadal functions. Mutations of genes expressed in the hypothalamus generally result in hypogonadotrophic hypogonadism, a condition of absent or deficient puberty owing to low serum gonadotrophin, Follicle Stimulating Hormone (FSH) and Luteinising Hormone (LH). The KAL1 gene is localized in the pseudoautosomal region of the Xp. Mutations like deletions and point mutations cause Kallmann's syndrome in males. It is an Xlinked recessive idiopathic condition, associated with hypogonadism and anosmia. Mutations in AHC gene is implicated in adrenal hypoplasia which causes delayed puberty and cryptochordism in males. Leptin (LEP) mutations posed irreversible pubertal delay [18,19]. Males with FSH $\beta$ mutations present with azoospermia, but puberty may be normal or absent in them [20]. SOX9 is a member of a family of transcription factors that contain a Sex determining Region of Y chromosome (SRY) - related HMG box (SOX). Mutations in SOX9 gene have been found in individuals who are chromosomally male but phenotypically female. Still, there are many genes need to be explored in terms of infertility [21,22].

\section{Cystic Fibrosis}

The men with Cystic Fibrosis (CF) have been associated with Congenital Bilateral Absence of the Vas Deferens (CBAVD) as a result of which spermatozoa are not transported to the urethra, a condition referred to as obstructive azoospermia. Mutations in the CFTR gene have also been identified in patients with CBAVD, which suggests that this condition is a primarily genital form of cystic fibrosis [23-25].

\section{Leydig Cell Hypoplasia}

Leydig cell hypoplasia is a rare autosomal recessive condition wherein the fetal Leydig cells are unresponsive to Human Chorionic Gonadotropin (hCG). The condition featured with hypoplasia of the Leydig cells, complete feminization of the external genitals and 
partial masculinization with micropenis. Leydig cell hypoplasia is caused by inactivating mutations in the LHCGR gene [26].

\section{XY Gonadal Dysgenesis}

Gonadal Dysgenesis (GD) can be classified as complete or partial. The gonads in partial GD may be marked by the presence of few tubular structures or fibrous tissues or may occur as streaks. In complete GD, male have a completely female phenotype with no gonadal development. However, complete GD has a higher risk for developing gonadoblastoma [27].

\section{Female Infertility}

\section{Advanced Maternal Age and Aneuploidy}

Advanced maternal age has been commonly associated with aneuploidy due to non-disjunction of chromosomes during meiosis. It is considered as main cause of embryonic loss and poor fertility. The "limited oocyte pool" means the lower number of antral follicles in older women's ovaries may cause the recruitment of suboptimal - premature or postmature - oocytes for ovulation. The number and distribution of chiasmata formed during early prophase I as well as weakened centromeric cohesion; establish a strong predisposition for aneuploidy [6]. 47, XXX syndrome, also known as trisomy X, is one of the most common causes of Premature Ovarian Insufficiency (POI). While, the majority of women with trisomy $\mathrm{X}$ present as normal, some suffer from POI or from malformations of the genitourinary tract [28].

\section{Turner's Syndrome}

Turner's Syndrome (TS) is characterized by a complete or partial absence of one $\mathrm{X}$ chromosome. The most frequent chromosome constitution is $45 \mathrm{X}$. A mosaic chromosome complement, the most common being $45 \mathrm{X} / 46 \mathrm{XX}, 46 \mathrm{XXq}$ or $46 \mathrm{XXp}$ deletions and a ring $\mathrm{X}$ chromosome complement can be identified in the syndrome. Thus, the syndrome might be attributable to a limited amount of genetic material in these chromosomes and is usually due to nondisjunction during meiosis. Most women with TS are infertile due to gonadal dysgenesis and a streak ovary composed of white fibrous stromal tissue containing no ova or follicular derivatives. However, at puberty, mostly those with mosaic karyotypes, have ovaries with a relatively low number of follicles, so that there is spontaneous pubertal development [23,30].

\section{Polycystic Ovary Syndrome}

Polycystic Ovary Syndrome (PCOS) is a complex and heterogeneous endocrine condition marked by hyperandrogenism, hyperinsulinemia, insulin resistance and chronic anovulation. The elevated insulin levels facilitate secretion of androgens from the ovaries and adrenal glands, leading to hyperandrogenism. Elevated levels of androgens lead to menstrual disturbances and infertility. As DNA methylation regulates gene transcription, forty genes have been shown to be differentially methylated in PCOS patients compared with the corresponding genes in normal individuals. Changes in methylation of EPHX1, LMNA, and GSK3A are associated with PCOS. Although, several genes have been associated with PCOS, there is no evidence to suggest that a unique gene or a dominant pathway is the sole causative factor $[6,31,32]$.

\section{Cystic Fibrosis}

Cystic Fibrosis (CF) is the most common life-shortening genetic disease caused by mutations in the gene encoding a cAMP-regulated chloride channel, the CF Transmembrane Conductance Regulator (CFTR). CF is a systemic illness that affects various organ systems including the pulmonary, endocrine, epithelial, gastrointestinal, pancreatic, immune and reproductive systems. Reduced fertility has also been observed in women with CF. The prominent hypothesis for the decreased fertility in CF females is viscous mucus in the cervix that may create a barrier to sperm passage. Additionally, CFTR is involved in secretion of endometrial and oviduct HCO3-, which is necessary for sperm capacitation. CFTR is also expressed in the cervix, oviduct, ovary and uterus, where it regulates fluid control in the female reproductive tract. CF is associated with menstrual irregularities, including amenorrhea, irregular cycles and anovulation [24,25,33].

\section{Single Gene Mutations}

FSH $\beta$ gene mutation has been shown to cause absent or incomplete breast development, low FSH and oestradiol, high LH and sterility in females [20]. Similarly, Xp11 gene deletions result in ovarian failure as well as affect menstrual function in women [19]. Fragile X syndrome is characterized by mental retardation, long faces, large ears and prominent jaws. The syndrome was first reported in 1969 with constriction of the long arm on the $\mathrm{X}$ chromosome. The critical gene for fragile X is FMR1 [34]. Many women with galactosemia manifest hypergonadotropic hypogonadism, presenting with secondary amenorrhea and premature ovarian failure. A candidate gene associated with galactosemia and endometriosis is the GALT gene [35]. Leiomyomas or fibroids are benign tumors found in the smooth muscle layers of the uterus. New studies using conventional and next-generation sequencing techniques identified mutations in the MED12 gene as a major contributor to leiomyoma [36]. Endometriosis is a complex disease, characterized by the inflammation and bleeding of the endometrium. It posed infertility and pain due to endometrial tissue in the pelvic region outside of the uterus. The candidate genes have been identified by genetic association and linkage studies are SNPs and CNVs. Among two Genome Wide Association (GWAS) studies conducted in Australia and Japan in 2011 and 2010, only one common locus was found in the 1 p36 region which contains WNT4, a gene responsible for cell proliferation and which plays a key role in embryogenesis involvement in endometriosis [3].

\section{Gonadal Dysgenesis}

Sex determination is controlled by complex molecular signaling and abnormalities in these signaling pathways can lead to gonadal dysgenesis. A well-known illustration of this type is $\mathrm{XX}$ female Gonadal Dysgenesis (XX-GD) which is genetically heterogeneous, but phenotypically identified by the presence of gonadal streaks, lack of spontaneous pubertal development, primary amenorrhea, uterine hypoplasia and hypergonadotropic hypogonadism. Ovarian insufficiency can range from lack of pubertal development to the onset of menopause before the age of 40 years. Mutations in FSHR, BMP15, NR5A1, EIF2B2, EIF2B5, HSD17B4, and HARS2 have been reported in XX-GD [37]. Ovarioleukodystrophy and 
Perrault syndrome are examples of syndromic cases of XXGD. Perrault syndrome is characterized by ovarian dysgenesis, sensorineural deafness, mental retardation, ataxia and cerebellar hypoplasia. Compound mutations at highly conserved amino acids in mitochondrial Histidyl tRNA Synthetase (HARS2) also cause this syndrome. These mutations implicate a role for the mitochondria in proper function of the ovaries [38].

\section{Premature Ovarian Failure}

Premature Ovarian Failure (POF) is defined as the onset of menopause in women under the age of 40 years. The symptoms include amenorrhea due to hypoestrogenism, elevated gonadotrophin levels and other menopause-related symptoms such as hot flushes, night sweats and vaginal dryness. POF is likely due to depletion of the follicles which could be because of a decreased number of oocytes being formed during development or an increased rate of oocyte atresia during the reproductive lifespan [39]. Paradoxically, the etiology of this disease is not clear and it is likely that the disease is caused by several factors. POF can be influenced by environmental and genetic factors. Irreversible damage to the ovaries during radiation therapy, chemotherapy or autoimmune disease conditions can cause POF. The X chromosome abnormalities and autosomal genetic defects can also cause POF [40]. A number of genes have been associated with POF include FMR1 and Bone Morphogenetic Protein 15 (BMP15). Among autosomal gene mutations often found in women with POF are AR, CDKN1B, CYP19A1, GDF9, FIGLA, FOXL2, FOXO1a, FOXO3a, INHA, LHX8, NOBOX, NANOS3, FSHR and SALL4 [41].

\section{Conclusion}

The genomic basis of infertility is very complex and is determined by many factors. These factors influence the development of gametes, reproductive organs, their physiology and the development of embryo and its further differentiation. The genetic disorders can affect males, females or both, causing infertility. Genetic disorders can be chromosomal, single gene mutations or can be multi-factorial. Extensive research has been conducted for having a better insight into the genomic basis of infertility. However, inspite of extensive research, there are no well-defined genes that can be used for genetic testing of infertility conditions. Thus, there is a need for newer diagnostic technologies to identify both new and known infertility genes. With the growing incidence of infertility and growing awareness of general population towards newer approach in the treatment of infertility, better understanding in the genetic control of infertility will help in planning treatment modality that would prove beneficial to the infertile couples.

\section{References}

1. Ganguly S, Unisa S (2010) Trends of infertility and childlessness in India: Findings from NFHS Data. Facts Views Vis Obgyn 2: 131-138.

2. Mascarenhas MN, Flaxman SR, Boerma T, Vanderpoel S, Stevens GA (2012) National, regional and global trends in infertility prevalence since 1990: A systematic analysis of 277 health surveys. PLoS Med 9(12): e1001356.
3. Zorrilla M, Yatsenko AN (2013) The genetics of infertility: Current status of the field. Curr Genet Med Rep 1(4): 247-260.

4. Ferlin A, Arredi B, Foresta C (2006) Genetic causes of male infertility. Reprod Toxicol 22(2): 133-141.

5. Dong Y, Du RC, Jiang YT, Wu J, Li LL, et al. (2012) Impact of chromosomal translocations on male infertility, semen quality, testicular volume and reproductive hormone levels. J Int Med Res 40(6): 2274-2283.

6. Singh V, Pakhiddey R (2015) Current scenario on genetic basis of infertility- A review. Acta Med Int 2(2): 149-154.

7. Hernandez D, Fisher EM (1996) Down syndrome genetics: Unravelling a multifactorial disorder. Hum Mol Genet 5: 1411-1416.

8. Stefanidis K, Belitsos P, Fotinos A, Makris N, Loutradis D, et al. (2011) Causes of infertility in men with Down syndrome. Andrologia 43: 353357.

9. Harton GL, Tempest HG (2012) Chromosomal disorders and male infertility. Asian J Androl 14(1): 32-39.

10. Kousta E, Papathanasiou A, Skordis N (2010) Sex determination and disorders of sex development according to the revised nomenclature and classification in 46, XX individuals. Hormones (Athens) 9(3): 218131.

11. Shah K, Sivapalan G, Gibbons N, Tempest H, Griffin DK (2003) The genetic basis of infertility. Reproduction 126(1): 13-25.

12. Liehr T, Weise A (2007) Frequency of small supernumerary marker chromosomes in prenatal, newborn, developmentally retarded and infertility diagnostics. Int J Mol Med 19(5): 719-731.

13. Manvelyan M, Rigel M, Monica S (2008) Thirty-two new cases with small supernumerary marker chromosomes detected in connection with fertility problems: Detailed molecular cytogenetic characterization and review of the literature. Int J Mol Med 21(6): 705-714.

14. Armanet N, Tosca L, Brisset S, Liehr T, Tachdjian G (2015) Small supernumerary marker chromosomes in human infertility. Cytogenet Genome Res 146(2): 100-108.

15. Klesert TR, Otten AD, Bird TD, Tapscott SJ (1997) Trinucleotide repeat expansion at the myotonic dystrophy locus reduces expression of DMAHP. Nat Genet 16(4): 402-406.

16. Sarkar PS, Paul S, Han J, Reddy S (2004) Six 5 is required for spermatogenic cell survival and spermiogenesis. Hum Mol Genet 13(14): 1421-1431.

17. Kim WB, Jeong JY, Doo SW, Yang WJ, Song YS, et al. (2012) Myotonic dystrophy type 1 presenting as male infertility. Korean J Urol 53(2): 134-136.

18. Montague CT, Farooqi S, Whitehead FP, Soos MA, Rau H, et al. (1997) Congenital leptin deficiency is associated with severe early-onset obesity in humans. Nature 387(6636): 903-908.

19. Layman LC (2002) Human gene mutations causing infertility. J Med Genet 39(3): 153-161.

20. Layman LC, Lee EJ, Peak DB, Namnoum AB, Vu KV, et al. (1997) Delayed puberty and hypogonadism caused by a mutation in the follicle stimulating hormone $\beta$-subunit gene. N Engl J Med 337(9): 607-611.

21. Clarkson MJ, Harley VR (2002) Sex with the SOX on: SRY and SOX9 in testis development. Trends Endocrinol Metab 13(3): 106-111.

22. Jedidi I, Ouchari M, Yin Q (2018) Autosomal single-gene disorders involved in human infertility. Saudi J Biol Sci 25(5): 881-887.

23. Sokol RZ (2001) Infertility in men with cystic fibrosis. Curr Opin Pulm Med 7(6): 421-426.

24. Ajonuma LC, Ng EH, Chow PH, Hung CY, Tsang LL, et al. (2005) Increased Cystic Fibrosis Transmembrane Conductance Regulator (CFTR) expression in the human hydrosalpinx. Hum Reprod 20(5): 1228-1234. 
25. Ahmad A, Ahmed A, Patrizio P (2013) Cystic fibrosis and fertility. Curr Opin Obstet Gynecol 25(3): 167-172.

26. Yamashita S, Tai P, Charron J, Ko C, Ascoli M (2011) The Leydig cell MEK/ ERK pathway is critical for maintaining a functional population of adult Leydig cells and for fertility. Mol Endocrinol 25(7): 1211-1222.

27. McCann-Crosby B, Mansouri R, Dietrich JE, McCullough LB, Sutton VR et al. (2014) State of the art review in gonadal dysgenesis: Challenges in diagnosis and management. Int J Pediatr Endocrinol 2014(1): 4.

28. Simpson JL, Rajkovic A (1999) Ovarian differentiation and gonadal failure. Am J Med Genet 89(4): 186-200.

29. Lippe B (1996) Turner's syndrome. In Sperling MA (Ed) Pediatric Endocrinology. WB Saunders Company, Alden Press, Philadelphia pp. 387-421.

30. Folsom LJ, Fuqua JS (2015) Reproductive issues in women with Turner syndrome. Endocrinol Metab Clin North Am 44(4): 723-737.

31. Barber TM, Franks S (2013) Genetics of polycystic ovary syndrome. Front Horm Res 40: 28-39.

32. Ndefo UA, Eaton A, Green MR (2013) Polycystic ovary syndrome. Pharm Ther 38(6): 336-355.

33. Oppenheimer EA, Case AL, Esterly JR, Rothberg RM (1970) Cervical mucus in cystic fibrosis: A possible cause of infertility. Am J Obstet Gynecol 108(4): 673-674.

ISSN: 2574-1241

DOI: 10.26717/BJSTR.2018.10.001984

Ansari AS. Biomed J Sci \& Tech Res

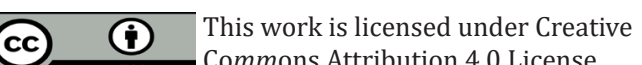

Submission Link: https://biomedres.us/submit-manuscript.php
34. Coffee B, Keith K, Albizua I, Malone T, Mowrey J, et al. (2009) Incidence of fragile $\mathrm{X}$ syndrome by newborn screening for methylated FMR1 DNA. Am J Hum Genet 85(4): 503-514.

35. Fridovich-Keil JL, Gubbels CS, Spencer JB, Sanders RD, Land JA, et al. (2011) Ovarian function in girls and women with GALT-deficiency galactosemia. J Inherit Metab Dis 34(2): 357-366.

36. Perot G, Croce S, Ribeiro A, Lagarde P, Velasco V, et al. (2012) MED12 alterations in both human benign and malignant uterine soft tissue tumors. PLoS One 7(6): e40015.

37. Zangen D, Kaufman Y, Zeligson S, Perlberg S, Fridman H, et al. (2011) XX ovarian dysgenesis is caused by a PSMC3IP/HOP2 mutation that abolishes coactivation of estrogen-driven transcription. Am J Hum Genet 89(4): 572-579.

38. Venkatesh T, Suresh PS, Tsutsumi R (2014) New insights into the genetic basis of infertility. Appl Clin Genet 7: 235-243.

39. Qin Y, Simpson JL, Chen ZJ (2017) Genetics of premature ovarian failure: New developments in etiology. 21: pp 17-39.

40. Shelling AN (2000) X chromosome defects and premature ovarian failure. Aust N Z J Med 30(1): 5-7.

41. Cordts EB, Christofolini DM, Dos Santos AA, Bianco B, Barbosa CP (2011) Genetic aspects of premature ovarian failure: A literature review. Arch Gynecol Obstet 283(3): 635-643.

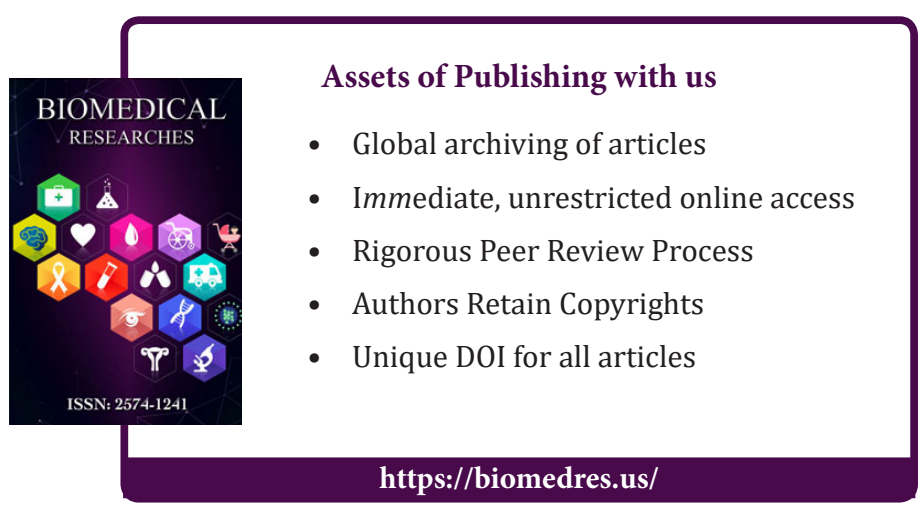

